\title{
BABURNÂME'DE HOCA UBEYDULLAH AHRAR
}

\section{Cengiz DEMIR*}

Geliş Tarihi: Nisan, 2016

\section{$\ddot{O} z$}

Muhammed Zahiruddin Babur (1483 - 1530), Hindistan'da 1526'dan 1858'e kadar hüküm süren Babur (Gürkaniler) İmparatorluğu'nun kurucusudur. Babur, devlet işlerinin yanında sanatsal ve akademik çalışmalara da ilgi duymuştur. Çağatay Türkçesi ile yazdığı Baburnâme olarak bilinen eserinde dönemin tarih ve kültürü hakkında pek çok bilgiler vermektedir. Sade ve akıcı dille, şahit olduğu olayları ve tanıdığı kişileri açıkça anlatmaktadır. Bu eserinde Babur, Hoca Ubeydullah Ahrar (1404 1490) hakkında da bazı kısa satır arası bilgiler vermektedir. Timur hanedanının (1357 - 1858) pek çok üyesi üzerinde etkiler bırakmış olan Hoca Ubeydullah Ahrar, döneminde ve sonrasında sultanların, âlimlerin ve halkın saygı duyduğu bir velidir.

Anahtar Sözcükler: Hoca Ubeydullah Ahrar, Hoca Ahrar, Babur, Baburnâme.

\section{KHWAJA UBAIDULLAH AHRAR IN THE BABUR-NĀMA}

Abstract

Muhammad Zahiruddin Babur (1483-1530) is the founder of the Gurkani (Mughal) Empire that ruled from 1526 to 1858 in northern India. Besides the governance, Babur was also interested in atristic and intellectual works. In his work the Babur-nāma written in Chagatai Turkic, he gives a lot of information about the history and the culture of his age. He depicts frankly the events he witnessed and people he knew. In that work, Babur gives some interlinear information about Khwaja Ubaidullah Ahrar (1404-1490). Khwaja Ubaidullah Ahrar, who had an influence on the several members of Timurid Dynasty (1357-1858) was a saint respected by sultans, scholars and people in his time and later.

Keywords: Khwaja Ubaidullah Ahrar, Khwaja Ahrar, Babur, the Baburnāma.

\section{Giriş}

Timur'un torunlarından Ömer Şeyh Mirza'nın (1456 - 1494) oğlu Muhammed Zahiruddin Babur (1483 - 1530), Fergana'nın Andican kasabasında doğmuştur. Babasının kaza sonucu ölümünün üzerine 12 yaşında Fergana tahtına oturan Babur, başlangıçta Semerkant'ta hüküm süren amcası Sultan Ahmed Mirza (1451 - 1494) ve Taşkent’te hüküm süren dayıs1 Sultan Mahmud Han (1462 - 1508) ile mücadele ettikten sonra, Özbek hükümdarı Muhammed Şeybani Han (1451 - 1510) ile mücadele etmiştir. Kızı Gülbeden'in ifadesiyle “Tam on bir sene

\footnotetext{
*Okt.; Kocaeli Üniversitesi, cdemir@kocaeli.edu.tr.
} 
Mavera-ün-nehir ülkesinde Çagatai, Timuri ve Özbek sultanlarıla mütemadiyen cenk ve cidalde bulundular. Kalem dili bu çarpışmaların sayısı ve beyanı hususunda aciz ve kasırdır'(Gülbeden, 1987: 115). 1504'te Kabil'i ele geçiren Babur, 1525'te Delhi sultanı İbrahim Ludi'nin (1480 - 1526) ordusunu mağlup ederek Pencap ve Lahor'u ele geçirmiş; 1526'da kuzey Hindistan'da 1858'e dek hüküm süren Babur (Gürkaniler) İmparatorluğu'nu kurmuştur. 1530'da oğlu Hümayun'u (1508 - 1556) yerine hükümdar ilan ettikten sonra Agra'da vefat etmiştir (Akar, 2005: 192 - 193; Konukçu, 1991: 395 - 396).

"O, bir insanda aynı zamanda bir araya gelemeyecek çeşitli kabiliyet ve değerleri ahenkli bir terkip içinde toplayabilmiş eşsiz bir hükümdar olarak yalnız Türk tarihinde değil, Doğu ve Batı âleminin büyük şahsiyetler galerisinde günümüzde hayranlıkla seyredilen bir portre olmuştur" (Akün, 1991: 396).

“Beş esere imzasını atmış bir edebiyatçı hükümdar”(Akün, 1991: 396) olan Babur 'un en önemli eseri Baburnâme, yaklaşık 18 yıllık kayıt eksik olmakla birlikte Fergana (1494 1503), Kâbil (1504 - 1520), Hindistan (1525 - 1529) devrelerini anlattığı bir hatırattır. "Sade ve samimi bir dille yazılmış olan bu eser Türk hatıra edebiyatının ve Çağatay nesrinin şaheserdir” (Ercilasun, 2013: 419).

Baburnâme, Babur'un kendi dili olan Çağatay Türkçesi ile yazılmış, daha sonra Ekber Şah (1542 - 1605) döneminde Farsçaya çevrilmiştir. İlk kısımları hatırat şeklinde, daha sonraki kısımları günlük şeklinde yazılmış, bazı kısımları ise elde mevcut değildir. Çevresindeki insanları, hanları ve beyleri, evliliklerini ve çocuklarını, kazandığı ve kaybettiği savaşları ve toprakları, isyanları, hasımlarını, içki sofralarını, gezilerini ve hatta yemek yerken kııılan dişini bile anlatmıştır Baburnâme’ de. Kendi ifadesiyle sadece gerçekleri yazmaya çalışmıştır.

Babur, babası Ömer Şeyh Mirza(1456 - 1494), amcası Sultan Mahmud Mirza (1453 1494), Hüseyin Baykara (1438 - 1506), Abdurrahman-1 Camî (1414 - 1492) ve Ali Şîr Nevayî (1441 - 1501) gibi o dönemin ünlü simaları hakkında detaylı bilgiler aktarır, onları portreleştirir. Babur'un kaleminden portreleşen simalardan biri olmasa da, Hoca Ubeydullah Ahrar hakkında da kayda değer satır arası bilgiler bulunmaktadır. Hoca Ubeydullah Ahrar, Nakşibendî (Hacegan) erenler silsilesinin en önemli halkalarından biridir.

Asıl adı Nâsıruddîn Ubeydullah b. Mahmud eş-Şaş̂̀’dir. Daha çok Ubeydullah Ahrar ve Hoca Ahrar olarak bilinmektedir. 1404'te Taşkent'in Bağıstan köyünde doğdu. Yirmi iki yaşına geldiğinde dayısı Hace İbrâhim onu ilim tahsili için Semerkant'a götürdü. Medrese eğitiminin yanı sıra tasavvufa meylederek Nizâmeddin Hâmûş, Seyyid Kasım-1 Tebrizî, Zeynüddin el-Hâfî gibi dönemin ünlü sufilerinin sohbetlerine katıldı. Daha sonra Semerkant'tan ayrılıp Herat'a 
gitti. Herat’taki ikametinin dördüncü yılında Nakşibendî şeyhi Ya‘kūb-i Çerhî’ye intisap etti. (Tosun, 2012: 19 - 20) Ali Şir Nevâyî’nin ifadesiyle: "Mevlana Ya'kub-i Çerhî kuddise sirruhudın irşadlar ve terbiyetler tapıpdurlar” (Nevayi, 1996: 257). Üç ay kadar Ya‘kub-i Çerhî'nin sohbetlerinde bulundu ve ondan hilafet aldı. Ertesi y1l 27 yaşında Taşkent'te irşat faaliyetine başladı, bir yandan da ziraat ve ticaretle meşgul oldu (Tosun, 2012: 19 - 20).

Semerkant'1 ele geçirip başşehir yapan Ebu Said Mirza Han'ın daveti üzerine Taşkent'ten ayrilarak Semerkant'a yerleşti. Burada da ziraat ve ticaretle uğraşarak Semerkant, Buhara, Taşkent vb. şehirlerde çok sayıda köy, bahçe, tarla, sulama kanalı satın aldı; bunların bir kısmını cami, medrese ve tekkelere vakfetti (Tosun, 2012: 19 - 20). Hoca Ubeydullah Ahrâr 1490 'da Semerkant'ta vefat etti ve burada defnedildi. Onunla devam eden Nakşibendiyye silsilesine Ahrariyye adı verilmiştir (Tosun, 2012: 19 - 20).

Hoca Ahrar'ın meşhur eseri, babasının kendisinden yüksek manevi makamlara ulaşmaya vesile olacak hususları yazmasını istemesi üzerine Farsça kaleme aldığı ahlak risalesi Vâlidiyye'dir. Bu eserle ilgili olarak Babur, Baburnâme'de bir hastalık sonucunda iyileşmek için teberrüken bu eseri manzum olarak tercüme ettiğini şöyle anlatmaktadır:

Pazar günü yeniden ateş geldi ve bir az titredim. Salı günü gecesi, Safer ayının yirmi yedisinde, Hoca Ubeydullah hazretlerinin Vâlidiye risâlesini nazma çevirmek hatırıma geldi. Hazretin ruhuna iltica edip, gönlümden: - "Eğer bu manzûme, o harzetin makbûlü olur - nitekim Kasîde-i bürde sâhibinin kasidesi makbûl olup, kendisi felç hastalığından kurtulmuştu - ve ben de bu hastalıktan kurtulursam, bu, nazmımın kabûl olunduğuna bir delil olur" - diye düşündüm. Bu niyetle, remel-i müseddesin darb ve arûzu mahbûn, bazen ebter ve bâzan mahbûn ve mahzûf olan vezninde - ki, Mevlâna Abdurrahman Câmî’nin Sübha'sı da bu vezindedir risalenin nazmına başladım ve o gece on üç beyit tertip ettim. Bililtizam her gün on beyitten daha az tertip edilmezdi. Gâlibâ bir gün ara verildi. Geçen sene de bir defa böyle bir hastalık gelmiş ve en az bir ay veya kırk gün devam etmişti. Tanrı inâyeti ve hazretin himmeti ile, Perșembe günü, ayın yirmi dokuzunda, bir az hafifledi; sonra bu hastalıktan kurtuldum. Cumartesi günü, Rebiülevvel ayının sekizinde, risalenin nazmı tamamlandı. Bir gün elli iki beyit yazıldı (Arat, 1987: 393 - 394).

\section{Baburnâme'de Hoca Ubeydullah Ahrar}

Ömer Şeyh Mirza'nın çevresinde iki önemli isim vardır: Hoca Ubeydullah Ahrar ve kayınpederi Yunus Han (1416 - 1487). Babur'un "Hoca Ubeydullah hazretlerinin müridi idi ve sohbetleri ile çok müşerref olmuştu. Hoca hazretleri de ona "oğlum" diye hitap ederdi" (Arat, 1987: 6) sözleriyle anlattığı babası Ömer Şeyh Mirza ve amcası Sultan Ahmed Mirza da "Hoca Ubeydullah hazretlerinin müridi idi” (Arat, 1987: 18).

Ömer Şeyh Mirza'ya Hoca Ahrar'ın “oğlum” diye hitap etmesinin Babur tarafından yazılmaya değer görülmesi Hoca Ahrar'ın yüksek itibarının göstergesidir. 
Ömer Şeyh Mirza, en büyük oğlu Babur doğduğunda Hoca Ahrar'dan oğluna isim talep etmiş ve o da Muhammed Zahiruddin ismini vermiştir. Hoca Ahrar'ın 1490 yılında 89 yaşında irtihalinde, Babur 7 yaşındadır ama Hoca Ahrar'ın onun üzerindeki etkisi ömür boyu sürmüştür (Beveridge, 1979: xxix).

Ali Şir Nevâyî, Maveraü’n-nehir'deki sultanların Hoca Ubeydullah Ahrar'ın müritleri olduğunu ve onun verdiği hükmü uyguladıklarını; hatta Horasan, Irak, Azerbaycan, Anadolu, Mısır, Çin ve Hindistan'daki sultanların da onun hükmüne itiraz etmediğini, emirlerini yerine getirdiklerini, mektuplarının bu sultanlar üzerinde çok etkili olduğunu; hatta hazretin çeşitli vesilelerle kendisine yazdığı mektupları bile ciltleyip teberrüken sakladığını belirtmektedir (Nevâyî, 1996: 257).

Hoca Ahrar'ın sultanlar üzerindeki etkisini göstermesi açısından; Semerkant'1 almak isteyen Sultan Mahmud Han ve Ömer Şeyh Mirza ile Sultan Ahmed Mirza'nın savaş meydanında barıştırılması ve antlaşma imzalanması hadisesi Hoca Ahrar'ın halifelerinden Mevlana Ali b. Hüseyin es-Safî’nin meşhur eseri Reşehât’ta özetle şöyledir: Ömer Şeyh Mirza ve Sultan Mahmud Han birleşerek Semerkant hükümdarı Sultan Ahmed Mirza üzerine yürümeye karar verdiler. Sultan Ahmed Mirza ordusuyla hareket edince beraberinde Hoca Ahrar'1 da götürmek için rica da bulundu. O seferde Hoca Ahrar 40 gün ordunun içinde Sultan Ahmed Mirza'nın yanındaydı. Hoca Ahrar, Sultan Ahmed Mirza'ya "Beni buraya niçin getirdiniz? Ben sipahi değilim. Eğer amacınız savaşmaksa benim burada ne işim var, yok eğer barış yapacaksanız niçin geciktiriyorsunuz? Artık daha fazla asker arasında durmaya mecalim kalmadı!" deyince Ahmed Mirza "Benim elimde olan bir şey yok! Bütün işler sizin görüşünüze bağlıdır. Siz nasıl uygun görürseniz bizim ona uymaktan başka çaremiz yoktur” şeklinde cevap verdi. Hoca Ahrar üç ordunun savaş için beklediği meydana bir çadır kurdurarak mirzaları orada buluşturup barışa ikna etti. Anlaşma gereği Taşkent'in yönetimini Sultan Ahmed Mirza'dan alarak Sultan Mahmud Han'a verdi (Es-Safi, 2010: 550-553). Burada kisaca aktarılan bu hadiseyi Reşehât yazarı Hoca Ahrar'ın halifelerinden Mevlana Kadı'dan ayrıntılı olarak nakletmektedir.

Reşehat'ta nakledilen diğer bir hadisede, Hoca Ahrar'ın muhtemel bir yağma ve savaş1 önlediği ve binlerce kişinin Müslüman olmasına katkıda bulunduğu anlatılmaktadır: Soğuk bir kış mevsiminde Sultan Ahmed Mirza'nın ricası üzerine Hoca Ahrar Türkistan seferine katıldı. Günlerce süren meşakkatli bir seferden sonra Şahruhiye’ye varıldı. 4000 kadar Moğol, 1000 kadar Özbek şehri yağmalamak kastıyla gelmişlerdi. Sultan Ahmed Mirza’nın bu kadar kişiye karşı koyacak askeri bulunmadığından Hoca Ahrar'dan yardım istediler. Hoca Ahrar bir grup ilim ehliyle birlikte giderek Moğol ve Özbek askerlerin emirleriyle konuştu ve onları ikna etti. 
Onlar da Hoca Ahrar'1n huzurunda Müslüman oldular ve tüm askerlerinin İslam'1 kabul etmesini sağladılar. Tüm esirlerini ve yağmaladıklarını Hoca Ahrar'a iade ettiler. Esirleri memleketlerine gönderen Hoca Ahrar, askerlerin İslam'1 öğrenmesi için bir hafız ve fakih görevlendirdikten sonra Şahruhiye’ye döndü (Es-Safi,2010: 615 - 616).

Hoca Ahrar üzerine yaptığı çalışmalarla bilinen Jo Ann Gross, Hoca Ubeydullah Ahrar'ın mektupları üzerine yaptığı çalışmasının önsözünde yirmi yıldan fazla zamanı Hoca Ahrar'ın müritlerinin, sultanların, saray çalışanlarının, âlimlerin, çiftçilerin gözündeki büyüklüğünün siyasi, ekonomik, sosyal ve dinî boyutlarını anlamaya harcadığını belirtmektedir (Gross, 2002: xi). Gross aynı eserinde Habibu's Siyer'den yaptığı alıntıda Hoca Ahrar'ın sultanlar nezdindeki yüksek itibar ve nüfuzunu ortaya koymaktadır: “Türkistan'ın uzak beldelerinden, hatta Azerbaycan ve Irak'ın şehirlerine kadar dönemin sultanları ve güçlü hanlarının hepsi bağlıları idiler ve her sözüne çok kıymet verirlerdi” (Gross, 2002: 2).

Reşehât yazarının bildirdiğine göre Hoca Ahrar'ın sultanlarla birlikte oluşunun amacı kendi ifadesiyle "Müslümanları zalimlerin şerrinden korumaktır" (Es-Safi 2010: 549).

Baburnâme'de sultanların önemli meselelerde Hoca Ahrar'a danışarak onun sözü üzerine hareket ettikleri görülmektedir: "Hoca hazretlerinin de her işte eli var idi; mühim meseleler ekseriya şeri'at yolu ile halledilirdi” (Arat, 1987: 18). Sultan Ahmed Mirza, Hoca Ahrar'ın isteğiyle Semerkant şehrini damga uygulamasından muaf tutmuştur (Es-Safi, 2010: 557). "Semerkand ahalisi, Sultan Ahmed Mirza'nın yirmi - yirmi beş sene süren saltanatı zamanında, müreffeh ve rahat yaşamışlardı, işlerin çoğu Hoca hazretleri tarafından, doğrulukla ve şeriata uygun olarak, halledilirdi” (Arat, 1987: 24).

Baburnâme'de Sultan Ahmed Mirza'nın anlatıldığı şu satırlarda sultanların Hoca Ahrar'ın huzurunda edebe çok riayet ettikleri açıkça görülmektedir: "Her zaman, bilhassa Hoca'nın sohbetinde, fevkalâde terbiyeli idi. Dediklerine göre, Hoca'nın meclisinde hiç bir vakit dizini dizi ile değiştirmemiştir. Bir defa Hoca hazretlerinin sohbetinde, âdeti hilâfına, ayağını değiştirerek oturmuş. Mirza kalktıktan sonra, Hoca hazretlerinin emri ile Mirza'nın oturduğu yere bakmışlar; bir kemik varmış" (Arat, 1987: 18).

Ebu Said Mirza'dan sonra Sultan Ahmed Mirza tahta geçince, Sultan Mahmud Mirza Semerkant'1 almak istemiştir. Hoca Ahrar, Sultan Mahmud Mirza'ya ve Emir Mezid Argun'a uyarı niteliğinde mektup yazmıştır. Hoca Ahrar'ın nasihatini kabul etmeyen Sultan Mahmud Mirza şehri kuşatınca, Sultan Ahmed Mirza şehirden çıkmak için Hoca Ahrar'dan izin istemiş; Hoca Ahrar, Sultan Ahmed'e izin vermeyerek onu zaferle müjdelemiştir (Es-Safi, 2010: 546 549). 
Babur, Sultan Mahmud Mirza için "Hoca Ubeydullah hazretlerini istihfaf ederdi" (Arat, 1987: 27) demektedir. Hoca Ahrar'dan gelen mektup ve nasihati kabul etmemesi de Sultan Mahmud Mirza'nın Hoca Ahrar'ı Babur'un dediği şekilde küçük gördüğünü göstermektedir. Kendisini küçük gören insanların halk arasında bulunması Hoca Ahrar'ın yüksek itibarını zedelemez. Hacegan büyüklerine göre, kâmil bir mürşidin aleyhinde insanların bulunmaması o zatın kemâlat eksikliğine işarettir çünkü Hacegan yolu peygamber yoludur ve bütün peygamberlerin aleyhinde insanlar hep olagelmiştir.

Sadece sultanlar ve hanlar değil, dönemin itibarlı emirleri ve beyleri de Hoca Ahrar'ın müritleridir. Sultan Ahmed Mirza'nın emiri Timur soyundan Derviş Bey "Hoca hazretlerinin müridi idi” (Arat, 1987: 2).

Hoca Ahrar, fakirlere ve miskinlere yardım eden, güçsüz ve mazlum kimseleri himaye ederek koruyan, onlara sığınak olan bir gönül eridir. Babur bu durumu "Evvelce fakir ve miskinler Hoca Ubeydullah hazretlerinin adamlarının himayesine iltica ederek, zulüm ve tecavüzden kurtulurlardı" (Arat, 1987: 23) şeklinde belirtmektedir. Olcott'un "sufi Robin Hood" (Olcott, 2007: 6) yakıştırmasını bir tarafa bırakacak olursak; Hoca Ahrar, döneminde vakıf sistemini işleterek yüzlerce akardan gelen kazancın hepsini halkın hizmetine adamıştır.

Babur, Baburnâme'de iki yerde rüya yoluyla Hoca Ahrar'ın kendisini uyardığını ve manevi destek verdiğini anlatmaktadır. Bu şekilde rüyada uyarılma veya desteklenme sadece Babur'a özgü değildir. Reşehât'ta benzeri rüya hadisesi hem Hoca Ahrar hem de Babur'un dedesi ve Hoca Ahrar'ın müridi Ebu Said Mirza (1424 - 1469) için nakledilmektedir. Hoca Ahrar rüyasında kendisine "İslam senin yardımınla kuvvetlense gerektir" demeleri üzerine, uyandığında bunun ancak sultanlarla olabileceği düşüncesiyle dönemin sultanı Abdullah Mirza (1410 - 1451) ile görüşmeye gider, ancak dervişin sultanla işi olmaz gerekçesiyle sultanla görüştürülmez.

O günlerde Babur'un dedesi Ebu Said Mirza da rüyasında Ahmed Yesevi'nin (1093 1166) Hoca Ahrar'a Mirza'nın yardım ve zafer kazanması niyetiyle dua etmesini işaret ettiğini görür. Ebu Said Mirza Taşkent'e gelerek Hoca Ahrar'ı bulur, elini öper ve duasını alır. Semerkant'a sefer için izin ister. İslam'a hizmet etmek şartıyla fethin kendisinin olacağ 1 müjdesini alır (Es-Safî, 2010: 539 - 540; Hanî, 2011: 602).

Ebu Said Mirza, 1451 yılında Semerkant üzerine sefer yaparak Abdullah Mirza'y1 mağlup etmiştir. Semerkant'1 payitaht yapan Ebu Said Mirza, Hoca Ahrar'1 Semerkant'a davet edince, sultanın bu ricasını kırmayan Hoca Ahrar Semerkant'a yerleşmiştir.

Yukarıda sözü edilen rüyalardan ilki Baburnâme'de şu şekilde aktarılmaktadır: 
Bir gün Esfidek kurganında, Dost Nâsır, Noyan Kökeltaş, Han Kulı, Kerimdâd, Şeyh Derviş, Husrev Kökeltaş ve Mirim Nâsır gibi, içkiler ile hep beraber oturuyorduk. Oradan buradan konuşuluyordu. Ben: - "Söyleyin bakalım, eğer Tanrı rast getirirse, Semerkand'ı ne zaman alırız?" - dedim. Bâzıları:- “ỉlk bahara alırız" - dediler. O zaman son bahar idi. Bâzıları bir ay, bâzıları kırk gün ve bâzıları da yirmi gün sonra dediler. Noyan Kökeltaş: - "On dört günde alırız" dedi. Tanrı rast getirdi ve tam on dört günde Semerkand'ı aldık.

O sırada garip bir rüya gördüm. Rüyamda, Hoca Ubeydullah hazretleri gelmişler ve ben istikballerine çıkmışım. Hoca gelip oturdular. Hoca'nın önüne, galiba biraz tekellüfsüz, sofra örtüsü yaymışlar ve bu yüzden hazretin hatırına bir şey gelmiş. Molla Baba, benim tarafıma bakıp, işaret ediyor. Ben de ima ile: - "Benden değildir, sofra örtüsünü koyan kusur etmiştir" - dedim. Hoca anladı ve bu mazeretimi kabul etti. Ayağa kalktılar; teşyie çıktım. Bu evin avlusunda, sağ veya sol kolumdan tutup, beni öyle yukarı kaldırdı ki, bir ayağım yerden kalktı.

Sofradakiler: - "Şeyh maslahat verdi" - dediler ve şu birkaç gün içinde Semerkand'ı aldım (Arat, 1987: 87).

Babur, Şeybani Han'a mağlup olup Semerkant'1 bıraktıktan sonraki dönemde dayıları Sultan Mahmut ve Sultan Ahmet Han'la tekrar Şeybani Han'a karşı hareket etmiş, Ahsı'da Şeybani Han'ın müttefiki Tenbel'in askerleriyle vuruşurken yaralanmış ve kaçarak Kernan köyüne saklanmıştır. Bu köyde gerçekleşen rüya ve kurtuluş hikâyesini Babur, Baburnâme'de şu şekilde anlatmaktadır:

Bende Ali: - "Kernan'm mahallelerinde tenha bahçeler var; orada hiç kimse bizim bulunabileceğimizi hatırına getirmez. Oraya gidip, Kadir-Birdi’ye adam gönderelim, oraya gelsin" - dedi. Bu niyetle atlara binip, Kernan'ın mahallerine geldim. Kış idi ve epeyce soğuktu. Bir eski kuzu derisi bulup getirdiler; giydim. Bir çanak darı çorbası getirdiler; içtim. Çok rahat ettim. Bende Ali'ye: - "Kadir-Birdi'ye adam gönderdin mi?" - dedim. — "Gönderdim" - dedi. Fakat bu alçak herifler, bu adamla birleşerek, onu Ahsi'ye, Tenbel yanına göndermişler. Duvarla çevrilmiş bir eve girip, ateş yakıp, bir müddet uykuya daldım. Bu herifler işgüzarlık edip, bana tekrar: - "Kadir-Birdi'den haber almadan, hareket edemeyiz. Burası mahalle arasıdır, kenarda tenha bahçeler vardır; oraya gidersek, hiç kimse bizim orada bulunabileceğimizi hatırına getirmez"- dediler. Gece yarısı ata binip, kenar bahçeye gittim. Baba Sayramî duvar üzerinden etrafı gözetliyordu. Öğle vaktine yakın duvardan inip, benim yanıma gelerek: - "Yusuf Daruga geliyor" — dedi. Buna çok üzüldüm ve - "Anla bakalım, benim burada olduğumu bilerek mi geliyor" - dedim. Çıktı ve konuştuktan sonra, gelip: - "Yusuf Daruga diyor ki, Ahsi kapısında bir yaya karşı çıktı ve padişahın Kernan'da filân yerde olduğunu söyledi. Ben başkalarına duyurmadan, bu yayayı, muharebede elime düşen Veli Hazançı ile birlikte, bir yere gizleyerek, kendim size koştum. Beylerin bu işten haberleri yoktur" - dedi. - "Sen ne düşünüyorsun?"- dedim. "Hepsi de hürmetkârlarınızdır, ne yapabilirler; gitmek lâzımdır. Sizi padişah yapacaklardır" dedi, _ "Bu kadar kavga ve muharebeden sonra, ne gibi bir itimatla gideyim" dedim. Böyle konuşurken, Yusuf gelip, önümde iki dizi üzerine çöküp: - "Size neden gizleyeyim; bundan Sultan Ahmed Bey'in haberi yoktur. Bayezid Bey sizin haberinizi alıp, beni gönderdi" dedi. Böyle deyince, bana garip bir hal oldu. Dünyada can korkusundan daha kötü bir şey yokmuş. Ben: - "Doğrusunu söyle, eğer iş biraz başka şekilde ise, abdest alayım" - dedim. Yusuf yemin etti, fakat onun yeminine kim inanır.

Kendimdeki takatsizliği düşündüm. Kalkıp, bahçenin bir köşesine gidip, kendi kendime düşünerek: - "însan eğer bin sene bile, yaşasa nihayet ölecektir" dedim. 
İster yüz sene, ister bir gün kal; bu gönül aydınlatan köşkü terk edeceksin.

Ölümü kabul ettim. Bu bahçeden bir su akıyordu. Abdest aldım. İki rekât namaz kıldım. Başımı münacata koyup, dilek dilerken, uykuya dalmışım. Rüyamda, Hoca Yahya'nın oğlu Hoca Ubeydullah hazretlerinin torunu olan Hoca Yâkub, ak ve kara nişanlı ata binip, kalabalık bir cemaatle karşıma çıktılar ve: — "Endişe etmeyiniz, Hoca Ahrar beni size gönderdiler: — "Biz onlara yardım gönderip, padişahlık makamına oturtmuşuz; bir yerde müşkilâta uğrarsa, bizi göz önüne getirip, yad etsin; biz orada hazır oluruz" - dedi. Hala bu anda muvaffakiyet sizin tarafinızdadır. Başınızı kaldırın, uykudan uyanın" - dedi. Bu vaziyette sevinçle uyandım. Yusuf Daruga ve yanında olanlar: — "Bahane edip, hiyle yapıyor; tutup bağlamak lâzımdır" - diye birbirleri ile görüşüyorlardı. Bu sözü işitip:- "Siz böyle konuşuyorsunuz, göreyim bakalım, hanginiz bana yaklaşabilir” dedim. Bu sözü söylerken, bahçenin duvarından, dışarıda kalabalık bir atlı kafilesinin ayak sesi geldi. Kutluk Barlas: - "Ahsi'den kaçıp çıkarken, sizden ayrıldıktan sonra, Endican'a geldim. Hanlar da Endican’a gelmişlerdi. Ben, bir rüya gördüm. Rüyamda Hoca Ubeydullah dediler ki, Babur padişah Kernan denilen köydedir; gidip onu getirin. Padişahlık makamı ona verilmiştir" — dedi. Ben bu rüyayı gördükten sonra, sevinerek, büyük ve küçük hana arzettim ve: — "Benim beş - altı küçük kardeşim ve oğlum var; bunlara birkaç yiğit katınız. Kernan tarafına gidip, haber alayım” dedim. Hanlar da: — "Biz de onun o tarafa gitmiş olacağını düşünüyoruz" dediler ve on kişi tayin ettiler ve: - "O tarafa gidip, iyice tahkik ederek, bir haber alın; hiç olmazsa, o taraftan bir haber bulabilirsiniz" - dediler. Böyle konuşurken, Baba-1 Pergarî: — "Ben de gidip arayayım" — dedi ve o da iki yiğit küçük kardeşi ile birlikte olduğu halde, hareket ettik. Bugün üçüncü gündür, yoldayız. EIhamdülillâh sizi bulduk" - dediler ve: "Yürüyün ata binin, bu bağlananları da alarak, gidelim. Burada durmak iyi değildir. Tenbel sizin buraya geldiğinizden haber almıştır. Ne yapıp yapıp gidelim de hanlara iltihak edelim" - dediler. Derhal ata binip Endican tarafına yürüyüverdik (Arat, 1987: 126-127).

Haydarabat nüshasını İngilizceye çeviren S. A. Beveridge bu olağanüstü rüya ve kurtuluşun esas metine dâhil olmadığını, uydurma olduğunu ve sonradan eklendiğini iddia etmektedir. Beveridge, Haydarabat ve Kehr yazmalarında bulunmasına, İlminsky ve Courteille tarafından da çalışmalarına alınmış olmasına rağmen, bu olayın uydurma olduğunu ve Cihangir Şah (1569 - 1627) tarafindan esere sonradan eklendiğini düşünerek Erskine ve Leyden gibi çevirisine almamış, dipnotlarla gerekçelerini açıklamıştır:

İlminsky ve Courteille'nin eksiksiz bir yazma üzerine çalışmadıklarını, çalışmalarının Elphinstone ve Haydarabat yazmalarıyla karşılaştırıldığında tutarsızlıkların görüleceğini düşünmektedir. Beveridge'a göre, Farsça tercümelerden birinin Çağatay Türkçesi'ne yeniden çevrilmesiyle oluşturulan Kehr - İlminsky metni garip bir biçimde bozuktur. Metindeki bu kusurlar Babur'un üslubu hakkında okuyucuya yanlış izlenim vermekte, okuyucu bu kurtarma hadisesini okurken esas metinden geçişi hissetmemektedir. Beveridge, görülen ayrıntılı rüyanın sıra dışı olması, rüyada "mirza" unvanını kullanan Timur hanedanı mensubu Babur için “padişah” sözcüğünün kullanılması, Hoca Yahya'nın Hoca Ya'kub isminde bir oğlunun olup olmadığının bilinmemesi, olayda geçen isimlerin Baburnâme' de daha önce geçmemesi, hanların Andican'da olmaması, bu bölümün ana metinle üslup olarak uymaması ve daha bazı 
gerekçelerle bu kısmın Baburnâme'ye ait olmadığı sonucuna ulaşmıştır (Beveridge, 1979: ix $\mathrm{xvi)}$.

\section{Sonuç}

Baba tarafindan Timur soyundan, anne tarafindan Cengiz Han'in soyundan olan Muhammed Zahiruddin Babur, Timur hanedanı, Moğollar, Orta Asya tarihi, Hindistan tarihi, Özbekistan tarihi, tasavvuf tarihi gibi pek çok alanda yapılan araştırmalarda bir tür kavşak rolü oynamaktadır. 1858'e dek süren Gürkaniler İmparatorluğu'nu kuran Babur, savaşlar ve devlet işlerinin yanında şiirle ve nesirle meşgul olmuştur.

Babur, dilindeki sadelik, canlılık ve ahenk ile Türk nesrinde mümtaz yere sahip olan Baburnâme adlı otobiyografisinde pek çok tarihî olaylar ve kişiler hakkında elde edilmesi zor bilgiler sunmaktadır. Detaylı olmasa da, Hacegan silsilesinin en gözde halkası olan Hoca Ubeydullah Ahrar hakkında birtakım kısa bilgiler Baburnâme'de bulunmaktadır. Bu kısa değinmelerde Hoca Ahrar'ın döneminde ne kadar itibarlı, sevilen, fakir ve mazlum dostu, sultanların bile huzurunda edeple oturduğu bir kutlu insan olduğu görülmektedir. Pek çok araştırmacının dikkatini çeken bu itibar ve sevginin kaynağında ise Hacegan büyüklerinin 'Hakka giden yol halka hizmetten geçer' düsturu olsa gerektir.

\section{Kaynaklar}

Abdulmecid HANÎ (2011). Hadaiku'l-Verdiyye (M. Emin FIDAN, çev.), İstanbul: Semerkand Yayıncılık, s.600 - 607

AKAR, A. (2005). Türk Dili Tarihi. İstanbul: Ötüken Neşriyat.

AKÜN, Ö. F. (1991). "Bâbürnâme". Türkiye Diyanet Vakfi İslam Ansiklopedisi. Ankara: Türkiye Diyanet Vakfı Yayınları, C. 4, 404 - 408.

BEVERIDGE, S. A. (1979). Babur-nama (Memoirs of Babur). New Delhi: Oriental Books Reprint Corporation

ERCILASUN, A. B. (2013). Başlangıçtan Yirminci Yüzyıla Türk Dili Tarihi. Ankara: Akçağ Yayınları.

Gazi Zahirüddin Muhammed Babur (1943). Vekayi Babur'un Hâtıratı I-II (Prof. Reşit Rahmeti Arat, çev.). Ankara: Türk Tarih Kurumu Yayınları.

GROSS, J. A. (2002). Tle Letters of Khwaja Ubayd Allah Ahrar and his Associates. Leiden: Brill.

GÜLBEDEN, (1987). Hümayunnāme. (Abdurrab Yelgar, çev. ), Ankara: Türk Tarih Kurumu Yayınlar1

KONUKÇU, E. (1991). "Bâbür". Türkiye Diyanet Vakfi İslam Ansiklopedisi. Ankara: Türkiye Diyanet Vakfi Yayınları, C. 4, 395 - 396.

LEYDEN, J. and ERSKINE, W. (1921). Memoirs of Zehir-ed-din Muhammed Babur (Annotated and Revised by Sir Lucas KING). London: Oxford University Press 
Mevlana Ali b. Hüseyin es-SAFÎ (2010). Reşehat (Hayat Pınarından Can Damlaları). İstanbul: Semerkand Yayıncilık

NEVAYİ, Ali Şir (1996). Nesayimü'l- Mahabbe min Şemayimi'l Fütüvve (Prof. Dr. Kemal ERASLAN, haz.). Ankara: Türk Dil Kurumu Yayınevi.

OLCOTT, M. B. (2007), Sufism in Central Asia, Washington: Carneige Endowment for International Peace.

TOSUN, N. (2012). "Ubeydullah Ahrar". Türkiye Diyanet Vakfi İslam Ansiklopedisi. Ankara: Türkiye Diyanet Vakfı Yayınları, C. 42, 19 - 20. 